\title{
Transferable $\beta$-Lactamase
}

\section{A NEW MECHANISM FOR IN VITRO PENICILLIN RESISTANCE}

\author{
IN STREPTOCOCCUS FAECALIS
}

\author{
Barbara E. Murray and Barbara Mederski-Samaroj, Department of Medicine \\ and the Program in Infectious Diseases and Clinical Microbiology, \\ University of Texas Medical School, Houston, Texas 77025
}

\begin{abstract}
A B S T R A C T Although enterococci are relatively resistant to penicillin, the mechanism of resistance is largely unknown and enzymatic inactivation does not play a role. In this study, an isolate of Streptococcus faecalis was found to have beta lactamase activity resulting in complete inactivation of penicillin. With a high inoculum, this strain was resistant to $>1,000 \mu \mathrm{g} /$ $\mathrm{ml}$ of penicillin. Penicillin resistance and beta lactamase activity were transferred by conjugation at a high frequency to an enterococcal laboratory recipient strain together with two plasmids of molecular size 34 $\times 10^{6}$ and $56 \times 10^{6}$, thus demonstrating the emergence of plasmid-mediated penicillin resistance in the genus Streptococcus.
\end{abstract}

\section{INTRODUCTION}

Enterococci are unique among streptococci because of certain biochemical features and because of their relative resistance to the effects of penicillin and ampicillin and their true resistance to cephalosporins, including the newer ("third generation") cephalosporins (1-4). The mechanism of resistance of enterococci to beta lactam agents is not completely understood, although some evidence suggests that there may be a lower affinity of the penicillin-binding proteins of enterococci for these antibiotics (5). Importantly, penicillinase production has never been found in enterococci nor in other penicillin-resistant streptococci $(6$, $7)$. In this report, we describe the finding of beta lac-

Address all correspondence to Dr. Barbara E. Murray, Program in Infectious Diseases, University of Texas Medical School, Houston, TX 77025.

Received for publication 11 May 1983. tamase activity in a clinical isolate of $S$. faecalis and the demonstration that this beta lactamase conjugally cotransfers with other resistance markers to a laboratory recipient strain.

\section{METHODS}

Bacterial strains. Enterococci were originally isolated in the microbiology laboratories of Hermann Hospital, the University of Texas Medical School in Houston, TX; the Massachusetts General Hospital, Boston, MA; and Ramathibodi Hospital, Bangkok, Thailand. Speciation was performed using standard biochemical testing (1) and serological grouping was performed using the Phadebact system (Pharmacia Diagnostics, Piscataway, NJ). Enterococcal strain HH22, isolated from a patient, was also identified as $S$. faecalis by $\mathrm{Dr}$. Richard Facklam of the Centers for Disease Control.

Antimicrobial testing. The minimal inhibitory concentration (MIC) ${ }^{1}$ of penicillin was determined by tube dilution with brain heart infusion (BHI) broth (Difco Laboratories, Detroit, MI) (8). Penicillin inactivation was demonstrated by bioassay using Micrococcus luteus. Penicillin (E. R. Squibb \& Sons, Princeton, NJ) in BHI broth at $4^{\circ}$ and at $37^{\circ} \mathrm{C}$ were used as controls. Penicillinase activity was also assayed using the chromogenic cephalosporin, nitrocefin (Glaxo Laboratories, Middlesex, England), by microiodometry, and a plate acidometric method (9).

Transfer of resistance and plasmid analysis. S. faecalis strain JH2-7 (thy Rif $^{\mathrm{R}} \mathrm{Fus}^{\mathrm{R}}$ ) (10), was used as the recipient. Conjugation experiments were performed by collecting donor and recipient strains on $0.45-\mu \mathrm{m}$ nitrocellulose filters, which were then incubated overnight at $37^{\circ} \mathrm{C}$ on BHI agar. The bacteria were resuspended in broth and plated on the appropriate selective media. Matings were also performed in the presence of DNase I, $100 \mu \mathrm{g} / \mathrm{ml}$ (Sigma Chemical Co., St. Louis, MO).

\footnotetext{
${ }^{1}$ Abbreviations used in this paper: $\mathrm{BHI}$, brain heart infusion; CFU, colony-forming units; MIC, minimal inhibitory concentration.
} 
Cleared lysates were prepared by the method of LeBlanc and Lee (11). Electrophoresis ws carried out in $0.7 \%$ agarose (Sigma Chemical Co.) and DNA in the gels was visualized by staining with ethidium bromide $(11,12)$.

\section{RESULTS}

S. faecalis strain HH22 was previously shown to be resistant to streptomycin, kanamycin, tobramycin, and gentamicin (MIC $>2,000 \mu \mathrm{g} / \mathrm{ml}$ ), to erythromycin $(\mathrm{MIC}>100 \mu \mathrm{g} / \mathrm{ml}$ ), and to tetracycline $(\mathrm{MIC}>30$ $\mu \mathrm{g} / \mathrm{ml})(12)$. While investigating the in vitro effects of the combination of aminoglycosides and penicillin, it was observed that with a high inoculum, this organism was not inhibited by the concentration of penicillin $(10 \mathrm{U} / \mathrm{ml})$ usually used in enterococcal synergy experiments (12-14). The results of susceptibility testing using different inocula of organisms are shown in Table I. HH22 was inhibited by $4 \mu \mathrm{g} / \mathrm{ml}$ of penicillin using $10^{3}$ colony-forming units $(\mathrm{CFU}) / \mathrm{ml}$ but grew readily in $1,024 \mu \mathrm{g} / \mathrm{ml}$ using $10^{7} \mathrm{CFU} / \mathrm{ml}$. Growth at a high inoculum was not observed with 30 other $S$. faecalis examined in this laboratory nor with numerous others in the literature (12-14); the MIC of penicillin for a representative strain, $\mathrm{HH} 54$ (also highly resistant to gentamicin), is also shown in Table I. The production of penicillinase, suggested by this inoculum effect (1516), was confirmed by demonstrating that $\mathrm{HH} 22$ inactivates penicillin (Fig. 1). Using a concentration of $32 \mu \mathrm{g} / \mathrm{ml}$ of penicillin and an inoculum of $10^{7} \mathrm{CFU} /$ $\mathrm{ml}$, rapid inactivation was observed, such that by $2 \mathrm{~h}$, there was no detectable penicillin activity remaining. $\mathrm{HH} 54$ and penicillin in $\mathrm{BHI}$ incubated at $37^{\circ} \mathrm{C}$ showed minimal loss (1-2\%) compared with the control stored at $4^{\circ} \mathrm{C}$.

TABLE I

MIC of Penicillin

\begin{tabular}{lcr}
\hline & Inoculum & MIC, 24 h \\
\hline & $C F U / m l$ & $\mu g / m l$ \\
HH22 & $10^{3}$ & 4 \\
$(+)^{\circ}$ & $10^{5}$ & 16 \\
& $10^{7}$ & $>1,024$ \\
HH54 & $10^{3}$ & 2 \\
$(-)$ & $10^{5}$ & 4 \\
& $10^{7}$ & 4 \\
JH2-7 & $10^{3}$ & 50.5 \\
$(-)$ & $10^{5}$ & $\leq 0.5$ \\
& $10^{7}$ & 2.0 \\
HH22 $\times$ JH2-7 & $10^{3}$ & 2 \\
$(+)$ & $10^{5}$ & 4 \\
& $10^{7}$ & 256 \\
\hline
\end{tabular}

- $(+)$ and $(-)$ indicate the presence or absence of penicillinase.

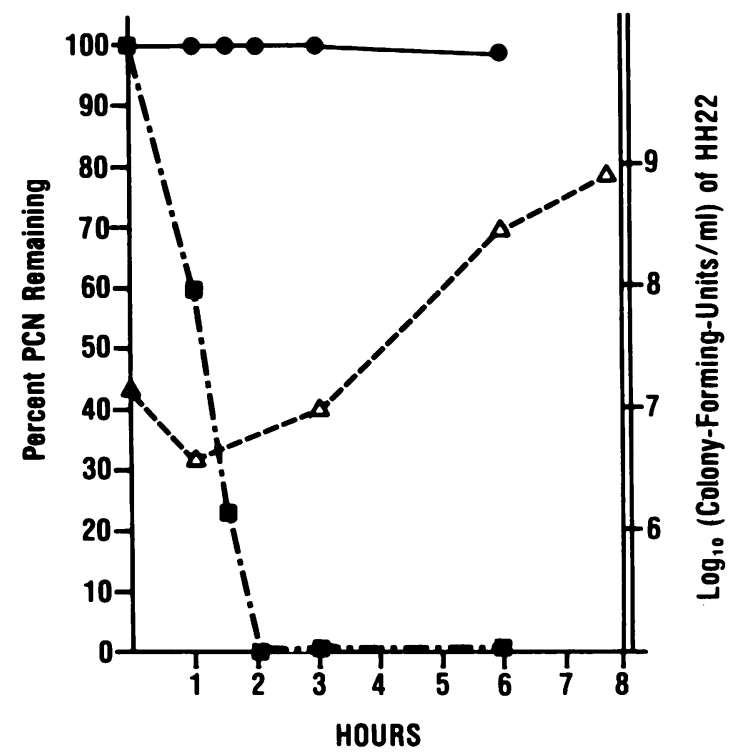

FIgURE 1 Inactivation of penicillin (PCN) by $S$. faecalis strain $\mathrm{HH} 22(\square)$ and $\mathrm{HH} 54(\bullet)$. The initial penicillin concentration was $32 \mu \mathrm{g} / \mathrm{ml}$. Percent penicillin activity was calculated by dividing the PCN concentration (determined by bioassay with Micrococcus luteus) by the PCN concentration in a refrigerated control. The growth curve of $\mathrm{HH} 22$ is also shown $(\triangle)$.

HH22 also gave a positive reaction using a chromogenic cephalosporin (nitrocefin), starch-iodine, and an acidometric plate method. Nitrocefin was then used to screen other enterococci for possible beta lactamase activity, some of which were also tested using one or both of the other two methods. These results were negative for a total of $\mathbf{4 2 9}$ other enterococci from three different geographic locations (249 from Houston, TX, 150 from Bangkok, Thailand, and 30 from Boston, MA).

We have previously reported that $\mathrm{HH} 22$ transfers gentamicin resistance to the recipient strain $\mathrm{JH} 2-7$ at a frequency of $6.7 \times 10^{-4}$ transconjugants per recipient (12). Resistance to kanamycin and tobramycin, but not streptomycin, tetracycline, or erythromycin, was cotransferred; moreover, 100 of 100 gentamicin-resistant transconjugants were beta lactamase producing. This transfer occurred in the presence of DNase but did not occur using chloroform-treated donors nor with cellfree supernatants of donor cells. We were unable to obtain penicillin-resistant transconjugants using penicillin for selection, presumably because of the inability of single cells to produce sufficient penicillinase to overcome the penicillin in the plates. As with $\mathrm{HH} 22$, transconjugant $\mathrm{HH} 22 \times \mathrm{JH} 2-7$ showed marked resistance to penicillin with a high inoculum (Table I) and also completely inactivated penicillin. Agarose gel electrophoresis of lysates of these strains and deriva- 
tives (Fig. 2) showed that the clinical isolate $\mathrm{HH} 22$ had three plasmids (molecular size $22 \times 10^{6}, 34 \times 10^{6}$, and $56 \times 10^{6}$ ); the transconjugant $\mathrm{HH} 22 \times \mathrm{JH} 2-7 \mathrm{had}$ received two of these $\left(34 \times 10^{6}\right.$ and $\left.56 \times 10^{6}\right)$.

\section{DISCUSSION}

Beta lactamase production is a common mechanism of resistance to beta-lactam agents. In many bacteria, such as Pseudomonas aeruginosa, beta lactamase production is an inherent species characteristic that is chromosomally mediated (17). In other instances, such as with Staphylococcus aureus, beta lactamase production is an acquired property $(18,19)$.

Despite over $40 \mathrm{yr}$ of penicillin usage, some species of common pathogenic bacteria have only recently been found to produce beta lactamase; the most obvious examples are Neisseria gonorrheae and Haemophilus influenzae. Other common pathogens such as Neisseria meningitidis and streptococci have never been shown to produce penicillinase. This is somewhat surprising since neisseriae closely related to the meningococcus have plasmid-mediated beta lactamase production and since many streptococci contain plasmids that mediate resistance to other antibiotics $(18$, 20,21 ).

In this work, a clinical isolate of $S$. faecalis has been shown to produce beta lactamase and to inactivate penicillin. Although enterococci are characteristically

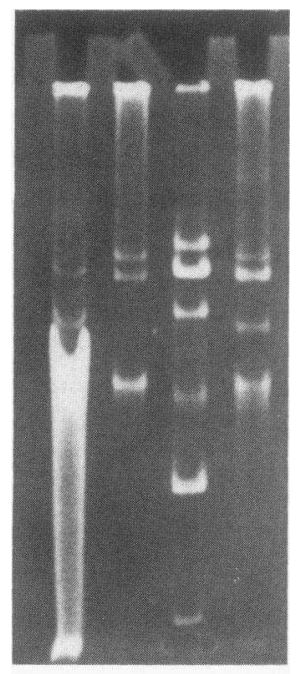

A B C D

Figure 2 Electrophoresis in $0.7 \%$ agarose of cleared lysates of HH22 (lanes $A$ and $D$ ), the transconjugant, $\mathrm{HH} 22 \times \mathrm{JH} 2$ 7 (lane $B$ ), and molecular size markers (lane $C$ ) including R1 $\left(62 \times 10^{6}\right)$, RP4 $\left(34 \times 10^{6}\right)$, S-a $\left(26 \times 10^{6}\right)$, RSF 1010 $\left(5.5 \times 10^{6}\right)$, amd pBR322 $\left(2.6 \times 10^{6}\right)$. resistant, or relatively resistant, to beta lactams by a mechanism that does not involve inactivation, the resistance of this isolate to penicillin far exceeds the resistance of other enterococci. More importantly, this beta lactamase is readily transferable to a laboratory strain, apparently by conjugation, since neither a transformation nor a transduction system has ever been demonstrated for enterococci, and since this strain transferred despite the presence of DNase, but not with cell-free extracts.

The clinical importance of enterococci, as a cause of urinary tract infections, wound infection, and endocarditis, is well recognized and the addition of beta lactamase production to the intrinsic resistance already seen in enterococci is of major concern. Another important concern is that the transferable penicillinase activity will disseminate into other streptococcal species, such as group A streptococci or Streptococcus pneumoniae for which penicillin is so commonly and effectively used. This is of particular concern since it is well known that some R-plasmids of streptococcal species can transfer to and from and stably exist in other streptococcal species and even S. aureus $(20,21)$. The appearance of transferable penicillinase in group D streptococci should, therefore, raise the level of suspicion that it may appear in other streptococci as well.

\section{REFERENCES}

1. Facklam, R. R. 1972. Recognition of group D streptococcal species of human origin species by biochemical and physiological tests. Appl. Microbiol. 23:1131-1139.

2. Toala, P., A. McDonald, C. Wilcox, and M. Finland. 1969. Susceptibility of group D streptococcus (Enterococcus) to 21 antibiotics in vitro. Am. J. Med. Sci. 258:416-430.

3. Moellering, R. C., Jr., and D. J. Krogstad. 1979. Antibiotic resistance in enterococci. In Microbiology-1979. D. Schlessinger, editor. American Society for Microbiology, Washington, DC. 293-298.

4. Georgopapadakou, N. H., and F. Y. Liu. 1980. Binding of beta-lactam antibiotics to penicillin-binding proteins of Staphylococcus aureus and Streptococcus faecalis. Antimicrob. Agents Chemother. 18:834-836.

5. Krogstad, D. J., and A. R. Parquette. 1980. Defective killing of enterocci: a property of antimicrobial agents acting on the cell wall. Antimicrob. Agents Chemother. 17:965-968.

6. Robins-Brown, R. M., M. N. Gaspar, J. I. Ward, I. K. Wachsmuth, H. J. Koornhof, M. R. Jacobs, and C. Thornsberry. 1979. Resistance mechanism of multiply resistant pneumococci: antibiotic degradation studies. Antimicrob. Agents Chemother. 15:470-474.

7. Parrillo, J. E., G. C. Borst, M. H. Mazur, P. Jannini, M. S. Klempner, R. C. Moellering, Jr., and S. E. Anderson. 1979. Endocarditis due to resistant viridans streptococci during oral penicillin chemoprophylaxis. $N$. Engl. J. Med. 300:296-300.

8. Washington, J. A., and V. L. Sutton. 1980. Dilution susceptibility test: agar and macrobroth dilution procedures. In Manual of Clinical Microbiology. E. H. Len- 
nette, A. Balows, E. Hausler, and J. P. Truant editors. Third ed. American Society for Microbiology, Washington, DC. 453-458.

9. Lucas, T. J. 1979. An evaluation of 12 methods for demonstration of penicillinase. J. Clin. Pathol. 12:10611065.

10. Jacob, A. E., and S. J. Hobbs. 1974. Conjugal transfer of plasmid-borne multiple antibiotic resistance in Streptococcus faecalis var. zymogens. J. Bacteriol. 117:360372.

11. LeBlanc, D. J., and L. N. Lee. 1979. Rapid screening procedure for detection of plasmids in streptococci. $J$. Bacteriol. 140:1112-1115.

12. Mederski-Samoraj, B. D., and B. E. Murray. 1983. High level resistance to gentamicin in clinical isolates of enterococci. J. Infect. Dis. 147:751-757.

13. Moellering, R. C. Jr., C. Wennersten, and A. Weinberg. 1971. Synergy of penicillin and gentamicin against enterococci. J. Infect. Dis. 124:S207-S209.

14. Calderwood, S. A., C. Wennersten, R. C. Moellering, Jr., L. Kunz, and D. Krogstad. 1977. Resistance to six aminoglycoside aminocyclitol antibiotics among enterococci and prevalence, evolution, and relationship to synergism with penicillin. Antimicrob. Agents Chemother. 12:401405.
15. Farrar, W. E., and P. K. Gramling. 1976. Antistaphylococcal activity and beta lactamase resistance of newer cephalosporins. J. Infect. Dis. 133:691-695.

16. Sabath, L. D., C. Garner, C. Wilcox, and M. Finland. 1975. Effect of inoculum and of beta lactamase on the anti-staphylococcal activity of 13 penicillins and cephalosporins. Antimicrob. Agents Chemother. 8:344-349.

17. Sykes, R. B., and M. Matthew. 1976. The beta lactamases of gram-negative bacteria and their role in resistance to beta-lactam antibiotics. J. Antimicrob. Chemother. 2:115-157.

18. Murray, B. E., and R. C. Moellering, Jr. 1978. Patterns and mechanisms of antibiotic resistance. Med. Clin. $N$. Am. 62:899-923.

19. Finland, M. 1971. Changes in the susceptibility of selected pathogenic bacteria to widely used antibiotics. Ann. NY Acad. Sci. 182:5-20.

20. Clewell, D. B. 1981. Plasmids, drug resistance, and gene transfer in the genus Streptococcus. Microbiol. Rev. 45:409-436.

21. Engel, H., N. Soedirman, J. Rost, W. van Leeuwen, and J. D. A. van Embden. 1980. Transferability of macrolide, lincosamide, and streptogramin resistance between group A, B, and D streptococci, Streptococcus pneumoniae, and Staphylococcus aureus. J. Bacteriol. 142:407-413. 